\title{
Complementary and Alternative Medicine among Inpatient Pediatric Under One Year of Age in Baghdad City-Iraq
}

\author{
Suadad J Al-Daboony, MBCHB-FICMS(CM) \\ Department of Community Medicine, Center Pediatric Hospital, Iraq
}

*Corresponding author: Suadad J Al-Daboony, MBCHB-FICMS (CM), Department of Community Medicine, Center Pediatric Hospital, Baghdad 6133, Iraq

\begin{abstract}
Background: Complementary \& alternative medicine popular in Iraq, its use from many age group but shortage of data is available about uses of traditional medicine in pediatric.
\end{abstract}

\begin{abstract}
Material and methods: The aim of this study to measure the prevalence of complementary and alternative medicine CAM (one type of CAM called saqua) use in acutely sick children (complaining from gastro intestinal symptom) and factors associated with it.
\end{abstract}

This is a cross-sectional study, hospital-based study in a tertiary center of Baghdad City- Iraq from the first January 2018 to January 2019. Children were assessed using a specially designed questionnaire, interview with one of child's family almost the mother or grandmother, face to face interview.

Data were analyzed using SPSS (statistical software version 20), Chi-square test for association between using CAM and not using. P-value of 0.05 was considered significant.

Results: Among the total 415 admitted children one year's olds or less complaining from gastro intestinal symptom, 36 $(8.6 \%)$ were using complementary and alternate medicine. The age distribution of the children using CAM less than first year, children were using CAM, age group less than one month $11(30.6 \%), 1$ to 6 months $22(61.1 \%)$ and from 6 months to 1 year $3(8.3 \%)$, male $22(61.1 \%)$, female 14 (38.9), about region urban $23(63.9 \%)$ and rural $13(36.1 \%)$, parent with low education state.

During period of hospitalization, observation and follow up was done, complication more in the children who use CAM (saqua), 9 (25\%) out of 36 using saqua complaining from complication compare with non-using 12(3. 2\%). Deaths increasing in the children which using saqua 21 (58.3\%) compare with non-using $8(2.11 \%)$.

\begin{abstract}
Conclusion: The usage of CAM concerning on value and believes, in this study was founded Complication more in children using CAM camper not using CAM (saqua), also number of death more in pediatric using CAM (saqua), so need awareness about it and more study about (saqua) one type of CAM.
\end{abstract}

\section{Keywords}

Complementary and alternative medicine, Children less than one year old, Baghdad City-Iraq

\section{Introduction}

\section{Traditional medicine}

It is the sum total of the knowledge, skill, and practices based on the theories, beliefs, and experiences indigenous to different cultures, whether explicable or not [1] also refers to health practices, approaches, knowledge and beliefs incorporating plant, animal and mineral based medicines, spiritual therapies, manual techniques and exercises, applied singularly or in combination to treat, diagnose and prevent illnesses or maintain well-being [2].

\section{Complementary medicine}

The terms "complementary medicine" or "alternative medicine" a broad set of health care practices that are not part of that country's own tradition or conventional medicine [1]. The high cost of drugs and increase in drug resistance to common diseases has caused the therapeutic approach to alternative traditional medicine as an option for concerted search for new chemical entities [2].

Citation: Al-Daboony SJ (2021) Complementary and Alternative Medicine among Inpatient Pediatric Under One Year of Age in Baghdad City-Iraq. Int J Pediatr Res 7:082. doi.org/10.23937/24695769/1510082

Accepted: December 14, 2021: Published: December 16, 2021

Copyright: (C) 2021 Al-Daboony SJ. This is an open-access article distributed under the terms of the Creative Commons Attribution License, which permits unrestricted use, distribution, and reproduction in any medium, provided the original author and source are credited. 
The strategy aims to support Member States in developing proactive policies and implementing action plans that will strengthen the role traditional medicine [3].

Herbal medicines include herbal preparations and finished herbal products that contain parts of plants, other plant materials or combinations [4]. Natural products and traditional medicines are of great importance. Such forms of medicine as traditional Chinese medicine, Ayurveda, Kampo, traditional Korean medicine, and Unani have been practiced in some areas of the world and have blossomed into orderly-regulated systems of medicine [5].

African traditional healthcare system is perhaps the oldest and the most assorted of all therapeutic systems. In many parts of rural Africa, traditional healers prescribing medicinal plants are the most easily accessible and affordable health resource available to the local community [6]. African traditional medicine is organized into three levels of specialty, namely divination, spiritualism, and herbalism. The traditional healer provides health care services based on culture, religious background, knowledge, attitudes, and beliefs that are prevalent in his community [7]. Greater use could be made of these medicinal plants at the primary health care level [8]. Traditional Chinese medicine is a traditional health practice originated from Chinese philosophy and religion [9]. The traditional Indian medicine remains the most ancient yet living traditions India is known for its traditional medicinal systemsAyurveda, Siddha, and Unani. The Ayurvedic concept appeared and developed between 2500 and 500 BC in India's [10].

Written history allows tracing back Mediterranean and European medical traditions to Greek antiquity [11]. Europe there is a very long history of traditional medicine that has a respectable historical and scientific dignity [12].

We define Traditional Arabic and Islamic Medicine (TAIM) as a system of healing practiced since antiquity in the Arab world within the context of religious influences of Islam and comprised of medicinal herbs, dietary practices, and mind-body therapy [13]. The study of herbs dates back 5,000 years to the ancient Sumerians, who described well-established medicinal uses for plants. In Ancient Egyptian medicine, the Ebers papyrus from c. $1552 \mathrm{BC}$ records a list of folk remedies and magical medical practices. In Iraq it is popular to use traditional \& sells remedies in different age groups for several indications [14]. Saqua is consider one of these remedies in Iraq its widely used among the low socioeconomic classes to treat neonates, infants \& children with abdominal pain \& diarrhea [14]. Many countries are still failing to implement the policy and program changes needed to improve access to affordable medicines [3]. It "inappropriate use of traditional medicines or practices can have negative or dangerous effects" and that "further research is needed to ascertain the efficacy and safety" of several of the practices and medicinal plants used by traditional medicine systems [15]. The World Health Organization has implemented a nine-year strategy to "support Member States in developing proactive policies and implementing action plans that will strengthen the role traditional medicine [16]. Herbal remedies have traditionally been used to treat both adults and children. Herbal remedies may offer a milder alternative to some conventional medicines [17].

\section{Material and Methods}

This is a cross-sectional observational study done in a tertiary hospital called center of pediatric teaching hospital in Baghdad City of Iraq, from January 2018 to January 2019. There are many types of traditional medicine used in Iraq but in this study it was highlighted on substance used to treated gastro-intestinal symptom especially diarrhea and vomiting, its type of CTM called saqua this is common name used in some region and karfaa in other, content of this saqua (herbal, parts of plant and animal, mineral material).

\section{Data gathering form}

In this study used questionnaires administrated to the parents or to one member of the family via faceto-face interview, using closed-ended and open-ended questions. The questionnaire includes: Age of the child, gender, address urban or rural region, education state of the mother and the father, types -quantitiesduration of using CAM, causes of taken, what squealy occurs after taken CAM.

\section{Inclusion and exclusion criteria}

Inclusion criteria which include all children admitted in the hospital aged one-year-old or less, complaining from gastro-intestinal symptom, used of traditional medicine (saqua).

Exclusion criteria: children more than one years of age. Complain from symptom other than GIT symptom, if using other types of CAM.

Using SPSS (statistical software version 20) \& using Chi-square test for association between using and not using. P-value of 0.05 was considered significant.

\section{Results}

Out of the total 415 admitted children one year's olds or less, $36(8.6 \%)$ were using complementary and alternate medicine (saqua).

The age distribution ranged from one year or less, children was using CAM age group less than one month $11(30.6 \%), 1$ to 6 months $22(61.1 \%)$ and from 6 months to 1 year $3(8.3 \%)$, male $22(61.1 \%)$, female $14(38.9)$, about region urban 23 (63.9) and rural 13 (36.1). 
The age group, gender and region of children using CAM and age group, gender and region of children not using CAM shown in Table 1.

Parents with low education state, education state of child's family using CAM shown in the Table 2.

During period of hospitalization, observation and fallow up the patient for final state of condition was found complication more in the children which use CAM (saqua), 9 (25\%) out of 36 complaining from complication in the children using saqua compare with non-using 12 (3.2\%).

Death increasing in the children which using saqua 21 (58.3) compere with non using 8 (2.11). Final state of hospitalized pediatric inpatient showed in the Table 3.

The association between gender of using and not using was shown in the Table 4.
More using of saqua in the age group 1-6 months, the association of age group between children was using CAM and not using showed in the Table 5.

The association between urban \& rural region of using CAM and not using showed in the Table 6 .

The association between the final state of pediatrics inpatient of using CAM \& not using present in the Table 7 which show children complaining from complication significant compare not using CAM (saqua), also number of death more in pediatric using CAM (saqua).

\section{Discussion}

The use of complementary and alternative medicine increasing among children [18]. In total 415 admitted children one year's olds or less, 36 (8.6\%) were using complementary and alternate medicine (saqua) for treatment GIT problem, prevalence was low and more in low educational state of child's family but found

Table 1: Age- gender \& region of children using \& not using CAM

\begin{tabular}{|c|c|c|c|c|c|c|c|c|c|c|c|c|c|c|}
\hline & \multicolumn{6}{|c|}{ Age } & \multicolumn{4}{|c|}{ Gender } & \multicolumn{4}{|c|}{ Region } \\
\hline & \multicolumn{2}{|c|}{ Less than 1 month } & \multicolumn{2}{|c|}{ 1-6 months } & $\begin{array}{r}6 \mathrm{mo} \\
\mathrm{y}\end{array}$ & $\begin{array}{l}\text { onths -1 } \\
\text { year }\end{array}$ & \multicolumn{2}{|c|}{ Male } & \multicolumn{2}{|c|}{ Female } & \multicolumn{2}{|c|}{ Urban } & \multicolumn{2}{|c|}{ Rural } \\
\hline & Frequency & $\%$ & Freq & $\%$ & Freq & $\%$ & Freq & $\%$ & Freq & $\%$ & Freq & $\%$ & Freq & $\%$ \\
\hline $\begin{array}{l}\text { Using C } \\
\& A M\end{array}$ & 11 & $30.6 \%$ & 22 & $61.1 \%$ & 3 & $8.3 \%$ & 22 & $61.1 \%$ & 14 & $38.9 \%$ & 23 & $63.9 \%$ & 13 & $36.1 \%$ \\
\hline $\begin{array}{l}\text { Not using } \\
C \text { \& AM }\end{array}$ & 64 & $16.9 \%$ & 123 & $32.45 \%$ & 192 & $50.65 \%$ & 167 & $44 \%$ & 212 & $56 \%$ & 154 & $41 \%$ & 225 & $59 \%$ \\
\hline
\end{tabular}

Table 2: Educations state of child's family using CAM.

\begin{tabular}{|l|l|l|l|l|}
\hline \multirow{2}{*}{} & \multicolumn{2}{|c|}{$\begin{array}{c}\text { Education state of } \\
\text { mother }\end{array}$} & & \multicolumn{2}{c|}{ Education state of } \\
\cline { 2 - 5 } & frequency & $\%$ & frequency & $\%$ \\
\hline No primary school & 24 & $66.7 \%$ & 22 & $61.1 \%$ \\
\hline Has primary school & 12 & $33.3 \%$ & 13 & $36.1 \%$ \\
\hline Has secondary school & & & 1 & $2.8 \%$ \\
\hline & 36 & $100 \%$ & 36 & $100 \%$ \\
\hline
\end{tabular}

Table 3: Final state of patient alive and well, dead or alive with complication.

\begin{tabular}{|l|l|l|l|l|l|l|l|}
\hline & \multicolumn{3}{|c|}{ Alive \& well } & \multicolumn{3}{c|}{ Dead } & \multicolumn{2}{c|}{ Alive with complication } & Total \\
\hline Using & 6 & $16.70 \%$ & 21 & $58.3 \%$ & 9 & $25 \%$ & 36 \\
\hline C \& AM & & & & & & & \\
\hline Not using & 359 & $94.72 \%$ & 8 & $2.11 \%$ & 12 & $3.2 \%$ & 379 \\
\hline Total & 365 & & 29 & & 21 & & 415 \\
\hline
\end{tabular}

Table 4: Association between gender of using CAM and not using.

\begin{tabular}{|l|l|l|l|}
\hline & Male & Female & \multicolumn{1}{c|}{ Marginal Row Totals } \\
\hline Using traditional medicine & 22 & 14 & 36 \\
\hline Not using & 167 & 212 & 379 \\
\hline Marginal Column Totals & 189 & 226 & 415 (Grand Total) \\
\hline
\end{tabular}

The chi-square statistic is 3.8526; The $p$-value is 0.049669; Significant at $p<0.05$. 
Table 5: The association between age group in using CAM with not using.

\begin{tabular}{|l|l|l|l|l|}
\hline & Less than 1 month & $\mathbf{1 - 6}$ months & More than $\mathbf{6}$ months & Row Totals \\
\hline Using traditional medicine & 11 & 22 & 3 & 36 \\
\hline Not using & 64 & 123 & 192 & 379 \\
\hline Column Totals & 75 & 145 & 195 & 415 (Grand Total) \\
\hline
\end{tabular}

The chi-square statistic is 23.6617; The $p$-value is $<0.00001$; The result is significant at $p<0.05$.

Table 6: The association between urban \& rural region of using CAM and not using.

\begin{tabular}{|l|l|l|l|}
\hline & Urban region & Uural region & Marginal Row Totals \\
\hline Using traditional medicines & 23 & 13 & 36 \\
\hline Group not using & 154 & 225 & 379 \\
\hline Marginal Column Totals & 177 & 238 & 415 (Grand Total) \\
\hline
\end{tabular}

The chi-square statistic is 7.2694. The $p$-value is 0.007014 . Significant at $p<0.05$.

Table 7: Final state of inpatient pediatrics between using CAM and not using.

\begin{tabular}{|l|l|l|l|l|}
\hline & Alive \& well & Dead & Complication & Row Totals \\
\hline Using traditional medicine & 6 & 21 & 9 & 36 \\
\hline Not using & 359 & 8 & 12 & 379 \\
\hline Column Totals & 365 & 29 & 21 & 415 (Grand Total) \\
\hline
\end{tabular}

The chi-square statistic is 202.4663; The $p$-value is $<0.00001$.

complication and death significant. complication more in the children which use CAM (saqua), 9 (25\%) out of 36 complaining from complication comparing to children not using saqua 12(3.2\%). Death increasing in the children which using saqua 21(58.3) compare with non-using $[2,11]$.

In India Among the included children, 161 were using complementary and alternative medicine. Of these, (70.2\%) were using complementary and alternative medicine for the current illness directly leading to admission whereas the rest were using at some point in past for other concerns [18].

(CAM) use among U.S. adults and Children whose parent used CAM were almost five times as likely (23.9\%) to use CAM as children whose parent did not use CAM (5.1\%). Between 2002 and 2007 increased use was seen among adults for acupuncture, deep breathing exercises, massage therapy, meditation, naturopathy, and yoga [19].

A frequency of CAM use was $87 \%$ in Turkish pediatric patients, CAM is extensively used in Turkish pediatric patients [20].

Parents of pediatric patients with chronic conditions such as epilepsy increasingly opt for complementary and alternative medicine (CAM) [21].

CAM plays a substantial role among parents of children referred to pediatric otolaryngology consultation [22].

We included 28 studies with survey data (collected from 1975 to 2005 the prevalence of any CAM use ranged from $6 \%$ to $91 \%$ [23].
Traditional medicines used in childbirth and for childhood diarrhoea in Nigeria's Cross River State, 11.3\% $(615 / 5425)$ of young children with diarrhoea were taken to traditional medical practitioners [24].

Up to one-half of children may use complementary health approaches (CHA). However, current prevalence in North America, variables associated with $\mathrm{CHA}$ use and caregiver perceptions of effectiveness are unclear [25]. Complementary or alternative medicine (CAM) use has greatly increased in the developed world, with paediatric prevalence figures between $1.8 \%$ and $80 \%$, depending on population and study design [26].

\section{Conclusion}

The usage of CAM concerning on value and believes, in this study was founded Complication more in children using CAM compere not using CAM (saqua), also the death more in pediatric using CAM (saqua), so need awareness about it.

\section{References}

1. World Health Organization (2002) WHO traditional medicine strategy 2002-2005. Geneva, Switzerland.

2. Fokunang $\mathrm{CN}$, Ndikum V, Tabi OY, Jiofack RB, Ngameni B, et al. (2011) Traditional medicine. Past, present and future research and development prospects and integration in the national health system of Cameroon. Afr $\mathrm{J}$ Tradit Complement Altern Med 8: 284-295.

3. Robinson MM, Zhang X (2011) Traditional Medicines: Global Situation, Issues and Challenges. The World Medicines Situation. ( $3^{\text {rd }}$ edn), WHO, Geneva, Switzerland.

4. World Health Organization (2019) WHO global report on traditional and complementary medicine 2019.

5. Yuan $\mathrm{H}, \mathrm{Ma}$ Q, Ye L, Piao G (2016) The traditional medicine 
and modern medicine from natural products Molecules 21 : 559.

6. Mahomoodally F (2013) Traditional medicines in Africa. An appraisal of ten potent African medicinal plants. Evid Based Complement Alternat Med 2013: 617459.

7. Ezekwesili-Ofili Josephine Ozioma, Okaka Antoinette Nwamaka Chinwe (2019) Herbal medicines in African Traditional Medicine.

8. (2001) Essential medicines and health products information portal.

9. Gu S, Pei J (2017) Innovating Chinese herbal medicine: From traditional health practice to scientific drug discovery. Front Pharmacol 8: 381.

10. Pandey MM, Rastogi S, Rawat AKS (2013) Indian traditional ayurvedic system of medicine and nutritional supplementation. Evid Based Complement Alternat Med 2013: 376327 .

11. Leonti M, Verpoorte R (2017) Traditional Mediterranean and European herbal medicines. J Ethnopharmacol 199: 161-167.

12. Firenzuoli F, Gori L (2007) European traditional medicine - International Congress - Introductory Statement. Evid Based Complement Alternat Med 4: 3-4.

13. Alrawi SN, Fetters MD (2012) Traditional arabic \& islamic medicine: A conceptual model for clinicians and researchers. Glob J Health Sci 4: 164-169.

14. Younus MM, Ali NK, Abdulqader HR (2017) Traditional medicine in Iraq is it a source of serious adverse events. IRAQI NMJ 3: 112-114.

15. World Health Organization (2008) Traditional Medicine: Definitions.

16. World Health Organization (2013) WHO traditional medicine strategy: 2014-2023.

17. Alkhazrajy LA, Habib HA, Alsudani ZI (2014) Perception of Iraqi primary health care providers about herbs in practice. European Journal of Botany, Plant Science and Phytology 1: $27-52$
18. Dhankar M (2018) Complementary and alternative medicine. A cross-sectional observational study in pediatric inpatients. J Evid Based Integr Med 23: 2515690X18765119.

19. Barnes PM, Bloom B, Nahin RL (2008) Complementary and alternative medicine use among adults and children: United States, 2007. Natl Health Stat Report 1-23.

20. Ozturk $\mathrm{C}$, Karatas $\mathrm{H}$, Längler $\mathrm{A}$, Schutze $\mathrm{T}$, Bailey $\mathrm{R}$, et al. (2014) Complementary and alternative medicine in pediatrics in Turkey. World J Pediatr 10: 299-305.

21. Doering JH, Reuner G, Kadish NE, Pietz J, Schubert-Bast S (2013) Pattern and predictors of complementary and alternative medicine (CAM) use among pediatric patients with epilepsy. Epilepsy Behav 29: 41-46.

22. Gruber M, Ben-Arye E, Kerem N, Cohen-Kerem R (2014) Use of complementary alternative medicine in pediatric otolaryngology patients: A survey. Int J Pediatr Otorhinolaryngol 78: 248-252.

23. Bishop FL, Prescott P, Chan YK, Saville J, Elm E, et al. (2010) Prevalence of complementary medicine use in pediatric cancer: A systematic review. Pediatrics 125: 768776 .

24. Sarmiento I, Zuluaga G, Andersson N (2016) Traditional medicine used in childbirth and for childhood diarrhoea in Nigeria's Cross River State: Interviews with traditional practitioners and a statewide cross-sectional study. BMJ Open 6: e010417.

25. Kalaichandran A, Barrowman N, Chan J, Toupin-April K, Vohra S, et al. (2018) Use and perceived effectiveness of complementary health approaches in children. Paediatrics \& Child Health 23: 12-19.

26. McCann LJ, Newell SJ (2006) Survey of paediatric complementary and alternative medicine use in health and chronic illness. Arch Dis Child 91: 173-174. 